\title{
A randomized, placebo-controlled trial of D-cycloserine for the enhancement of social skills training in autism spectrum disorders
}

Noha F. Minshawi ${ }^{1}$, Logan K. Wink², Rebecca Shaffer ${ }^{2}$, Martin H. Plawecki ${ }^{1}$, David J. Posey ${ }^{3}$, Hai Liư ${ }^{4}$, Sarah Hurwitz ${ }^{5}$, Christopher J. McDougle ${ }^{6}$, Naomi B. Swiezy ${ }^{1}$ and Craig A. Erickson ${ }^{2 *}$

\begin{abstract}
Background: Researchers have demonstrated that D-cycloserine (DCS) can enhance the effects of behavioral interventions in adults with anxiety and enhances prosocial behavior in animal models of autism spectrum disorders (ASD). This study extended upon this background by combining DCS with behavioral social skills therapy in youth with ASD to assess its impact on the core social deficits of ASD. We hypothesized that DCS used in combination with social skills training would enhance the acquisition of social skills in children with ASD.

Methods: A 10-week, double-blind, placebo-controlled trial of DCS (50 mg) given 30 min prior to weekly group social skills training was conducted at two sites. Children with ASD were randomized to receive 10 weeks (10 doses) of DCS or placebo in a 1:1 ratio.

Results: No statistically significant difference attributable to drug treatment was observed in the change scores for the primary outcome measure, the Social Responsiveness Scale (SRS), total score $(p=0.45)$, or on secondary outcome measures.

Conclusions: The results of this trial demonstrated no drug-related short-term improvement on the primary outcome measure, or any of the secondary outcome measures. However, an overall significant improvement in SRS total raw score was observed from baseline to end of treatment for the entire group of children with ASD. This suggests a need to further study the efficacy of the social skills training protocol. Limitations to the current study and areas for future research are discussed.
\end{abstract}

Trial registration: ClinicalTrials.govNCT01086475

Keywords: D-cycloserine, Autism spectrum disorders, Social skills training, Social deficits

\section{Background}

Autism spectrum disorders (ASD), including autistic disorder, Asperger's disorder, and pervasive developmental disorder not otherwise specified (PDD-NOS), have received increasing attention from researchers, clinicians, and the public since autism was first described by Leo Kanner in 1943 [1]. The diagnosis of ASD is characterized

\footnotetext{
* Correspondence: craig.erickson@cchmc.org

${ }^{2}$ Cincinnati Children's Hospital Medical Center, University of Cincinnati

College of Medicine, 3333 Burnet Avenue MLC 4002, Cincinnati, OH 45229,

USA

Full list of author information is available at the end of the article
}

by core social and communication deficits, as well as restricted, repetitive behaviors. In recent years, the rates of ASD have escalated, with the most recent Centers for Disease Control and Prevention data estimating prevalence at 1 in 68 children in the USA [2]. While some successful pharmacological and behavioral interventions have been identified for the treatment of hyperactivity/inattention and irritability associated with ASD [3, 4], little progress has been made in the effective treatment of primary social and communication deficits. The limited success of clinical trials targeting core social impairment in ASD is likely in part due to the heterogeneity of ASD, difficulty 
quantitatively tracking treatment response, and high placebo response rates [5]. Regardless, the lack of viable treatments is particularly concerning given that pervasive social impairment in ASD can limit lifelong functioning and independence [6].

Research in psychiatric disorders has led to some advances in ASD research. Specifically, a parallel is frequently drawn between schizophrenia and ASD due to similarity between the negative symptoms of schizophrenia and social withdrawal seen in ASD, as well as the implication of glutamate dysregulation in both disorders [7]. Consequently, several targeted treatment trials in both ASD and schizophrenia have focused on modulating glutamate neurotransmission $[5,8]$. D-cycloserine (DCS), a partial agonist of the $\mathrm{N}$-methyl-D-aspartate (NMDA) glutamate receptor and a Food and Drug Administrationapproved treatment for tuberculosis, has been researched for treatment of negative symptoms of schizophrenia with mixed results [8-12]. In ASD, a single-blind pilot study of DCS in children and adults (mean age of 10 years) found that DCS was associated with a clinically significant reduction in social withdrawal and increase in social responsiveness compared to a placebo control [13]. However, a double-blind, placebo-controlled trial of daily dosing of DCS in 88 children with ASD found no significant difference in measures of social withdrawal or global severity ratings during 8 weeks of daily treatment [14].

Glutamatergic neurotransmission has also been of interest in the treatment of anxiety disorders $[15,16]$. A growing body of preclinical and clinical research has demonstrated the ability of DCS to enhance learning in the treatment of anxiety symptoms [17]. The mechanism believed to be responsible for this effect is the enhancement of learned extinction of fear responses via combination cognitive behavior therapy (CBT) and DCS treatment $[17,18]$. Results have shown that DCS plays an augmentative role in the learning that takes place during $\mathrm{CBT}$ and therefore leads to greater success than when $\mathrm{CBT}$ is used alone.

The promising results from anxiety studies focused on extinction-based learning, as well as the role of DCS in other forms of learning, have subsequently led to the investigation of the role of DCS in the enhancement of social learning in animal models of ASD. Modi and Young [19] demonstrated that DCS combined with social learning paradigms in mice increased prosocial bonding and partner selection. This model of social learning may be similar to the social learning that takes place during social interactions and behavioral skills training in individuals with ASD. However, no studies of combined DCS plus nondrug therapy have been published in children with ASD. Based on this background, we investigated DCS treatment in combination with behavior therapy in youth with ASD. We hypothesized that DCS used in combination with social skills training utilizing the technology of applied behavior analysis (ABA), the most empirically supported behavioral intervention for ASD [20], would enhance the acquisition of social skills in children with ASD. The social skills training curriculum involved a combination of didactic instruction in the form of social stories [21, 22], discussions, discrimination training tasks, as well as performance and feedback-based instruction, such as role playing and modeling of skills. Typically developing peers were also incorporated as models in all groups. Social skills training that includes the use of typically developing peers as models and agents of intervention has been shown to increase the social interactions of children with ASD [23, 24]. The social skills group curriculum being utilized in this study was previously investigated via a pilot feasibility study with eight children with ASD and four typically developing peers. This pilot study used the Triad social skills assessment (TSSA) [25], social skills measure, as the primary outcome and evaluated $8 \mathrm{~h}$ of intervention. Children who participated in the social skills training demonstrated a significant improvement in overall social skill ability on the TSSA at post-test $(p<0.05)$. The children with ASD showed significant improvement in understanding emotions, initiating interactions, responding to interactions, and general social competency [26]. We additionally hypothesized that children treated with DCS would show greater improvement in social functioning from social skills training than those taking placebo.

\section{Methods}

\section{Study design}

A 10-week, double-blind, placebo-controlled trial of low dose (50 mg) DCS given 30 min prior to weekly group social skills training was conducted at two sites, Indiana University School of Medicine and Cincinnati Children's Hospital Medical Center. Children with ASD were randomized to receive 10 weeks (10 doses) of DCS or placebo in a 1:1 ratio. All children received 10 weeks of manualized social skills training. Children were further divided into two age groups, 5-7 and 8-11 years, for the purposes of keeping social skills groups more homogeneous. Each social skills group included up to four children with ASD and two typically developing peer models (TPs) in the same age group. The TPs participated in all group activities but did not take DCS or placebo. Adverse events (AEs) and interval history were collected prior to dosing, and outcome measures were administered at baseline, week 6 , and week 11 . This trial was approved by the Institutional Review Board at each site.

\section{Participants}

Sixty-seven children with ASD ages 5-11 years participated in the study along with 34 typically developing, 
same-aged children who served as TPs. One subject with ASD was excluded from the analyses due to early dropout prior to taking the study drug. Participants were recruited from academic autism treatment centers, local schools, and community organizations. Written informed consent was obtained from legal guardians, and assent was obtained when participants were able. Diagnosis of ASD was made through administration of the Autism Diagnostic Observation Schedule [27, 28], Autism Diagnostic InterviewRevised [29], and clinical interview using the Diagnostic and Statistical Manual of Mental Disorders, Fourth Edition, Text Revision (DSM-IV-TR) [30] criteria for autistic disorder, Asperger's disorder, or pervasive developmental disorder not otherwise specified (PDD-NOS).

Subjects with ASD were required to have an intellectual quotient greater than 70 on the Stanford-Binet 5th Edition [31] (SB-V) and a communication standard score greater than 70 on the Vineland Adaptive Behavior Scale 2nd Edition (VABS-II) [32] survey edition. These criteria were included to ensure that participants did not have cognitive or language deficits that could interfere with their ability to participate in group social skills training. Additional inclusion criteria included a Triad social skills assessment (TSSA) [25] score of $70 \%$ or less on both parent questionnaire and child assessment, significant social impairment as measured by a $T$ score of 60 or greater on the Social Responsiveness Scale (SRS) [33] and Clinical Global Impression-Severity (CGI-S) scale score of at least four (moderately ill). The CGI-S is a clinician-rated global assessment of symptom severity. The CGI-S item is rated on a scale from 1 to $7(1=$ normal, not at all ill; $2=$ borderline ill; $3=$ mildly ill; $4=$ moderately ill; $5=$ markedly ill; $6=$ severely ill; $7=$ among the most extremely ill patients). Rater training was conducted with gold standard vignettes and inter-rater reliability of $80 \%$ or greater was established.

Study participants were required to remain on stable psychotropic medication dosing targeting symptoms associated with ASD (e.g., insomnia, inattention, hyperactivity, anxiety, irritability) for a minimum of 2 weeks (with the exception of 4 weeks for fluoxetine) prior to randomization. Potential participants were excluded if they were taking more than two psychotropic medications or if they were currently taking a glutamatergic modulator (e.g., riluzole, memantine, acamprosate, topiramate, amantadine). In addition, concomitant psychosocial treatments could not include group social skills training outside of the study, and all the therapies were required to have been stable for at least 90 days prior to randomization.

The TPs were screened with the Child Symptom Inventory-4 [34] to ensure that they did not have a history of psychiatric symptoms that were currently affecting social skills (e.g., attention-deficit/hyperactivity disorder, oppositional defiant disorder, schizophrenia, ASD, social anxiety disorder, and major depression). The child's appropriateness for inclusion in the social skills groups (e.g., absence of social, behavioral, or language problems) was also assessed by a trained clinician. Parents of TPs provided informed consent and TPs provided assent.

\section{Social skills training}

Social skills groups were conducted following a manualized curriculum adapted for use in the present study. The curriculum utilized ABA-based methodologies, including shaping, incidental teaching, positive reinforcement, and visual schedules, as well as social stories and weekly parent-mediated homework assignments.

Sessions focused on a specific social skill topic each week: greetings, emotions, conversations, review, and saying good-bye. The curriculum included a variety of techniques that have been shown to help children with ASD learn social skills. A sample curriculum is provided in Table 1. Specific techniques included sorting examples of appropriate and inappropriate behaviors, reading social stories, engaging in role-plays, labeling flash cards, engaging in art activities, and playing various games. Minor modifications were made to curriculum based on the age group (5-7 or 8-11 years old) to enhance understanding and developmental appropriateness. Social groups were facilitated by masters or doctoral-level clinicians with expertise in ASD and ABA. Therapists were trained in the curriculum by a lead therapist (the study's principle investigator), and significant therapist overlap occurred both within and across study sites to address consistency in therapist techniques. However, treatment fidelity data was not collected.

The TPs assisted in modeling and reinforcing appropriate behavior during each group session. The TPs were recruited from local school districts and via media advertisements. Prior to the start of social skills training, TPs were educated in a separate session. An introduction to behaviors associated with ASD was presented, along with an overview of the social skills curriculum and weekly schedule. In addition, TPs engaged in role play with the clinicians to practice appropriate skills and corrective feedback was provided. A social story on ASD was also provided for the TPs to review at home with their parents prior to the first social skills group.

\section{Primary outcome}

The primary outcome measure of the ASD phenotype and social interactions in participants with ASD was the parent-rated SRS total raw score. The SRS is a standardized, 65-item measure of the core symptoms of ASD where each item is scored on a 4-point scale, which has been used extensively in ASD research [35-38]. The SRS was administered at screen, baseline, week 6 (after 5 weeks 
Table 1 Sample characteristics at baseline

\begin{tabular}{|c|c|c|c|}
\hline Characteristics & DCS $(n=34)$ & Placebo $(n=33)$ & $\mathrm{p}$-value \\
\hline \multicolumn{4}{|l|}{ Demographics } \\
\hline Age (years), mean (SD) & $8.38(1.93)$ & $8.25(1.73)$ & .76 \\
\hline Sex, n (\%) male & $28(82.35)$ & $27(81.82)$ & .95 \\
\hline \multicolumn{4}{|l|}{ Clinical Variables } \\
\hline \multicolumn{4}{|l|}{ Stanford-Binet V, mean (SD) } \\
\hline Full Scale IQ & $92.42(17.76)$ & $87.30(15.74)$ & .22 \\
\hline NonVerbal IQ & $95.15(18.03)$ & $90.82(15.19)$ & .30 \\
\hline Verbal IQ & $90.85(18.97)$ & $85.45(16.83)$ & .23 \\
\hline $\begin{array}{l}\text { VABS-II Expressive Language } \\
\text { subscale standard score, } \\
\text { mean (SD) }\end{array}$ & $87.38(13.36)$ & $84.55(14.94)$ & .42 \\
\hline $\begin{array}{l}\text { Clinical Global Impression- } \\
\text { Severity }\end{array}$ & $4.03(0.18)$ & $4.06(0.24)$ & .58 \\
\hline \multicolumn{4}{|l|}{ Diagnosis, n (\%) } \\
\hline PDD-NOS & $12(35.29)$ & $15(45.45)$ & .40 \\
\hline Autistic Disorder & $3(8.82)$ & $5(15.15)$ & $.48^{\mathrm{a}}$ \\
\hline Asperger's Disorder & $19(55.88)$ & $13(39.39)$ & .18 \\
\hline \multicolumn{4}{|c|}{ Concomitant medications, n (\%) } \\
\hline Antipsychotics & $8(23.53)$ & $8(24.24)$ & .95 \\
\hline Alpha-2 Agonists & $6(17.65)$ & $8(24.24)$ & .51 \\
\hline Stimulants & $14(41.18)$ & $11(33.33)$ & .51 \\
\hline Sleep Aids & $9(26.47)$ & $7(21.21)$ & .61 \\
\hline Mood Stabilizers & $1(2.94)$ & $2(6.06)$ & $.61^{\mathrm{a}}$ \\
\hline Glutamatergic Modulators & $1(2.94)$ & $0(0.00)$ & $1.00^{\mathrm{a}}$ \\
\hline Other & $3(8.82)$ & $1(3.03)$ & $.61^{\mathrm{a}}$ \\
\hline \multicolumn{4}{|l|}{ Concomitant treatment, n (\%) } \\
\hline Speech Therapy & $19(55.88)$ & $16(51.52)$ & .72 \\
\hline Occupational Therapy & $12(35.29)$ & $15(45.45)$ & .40 \\
\hline Behavioral Therapy & $9(26.47)$ & $9(27.27)$ & .94 \\
\hline Other Psychotherapy & $1(2.94)$ & $2(6.06)$ & $.61^{a}$ \\
\hline Physical Therapy & $0(0.00)$ & $2(6.06)$ & $.24^{\mathrm{a}}$ \\
\hline Social Skills Training & $3(8.82)$ & $2(6.06)$ & $1.00^{\mathrm{a}}$ \\
\hline Music Therapy & $0(0.00)$ & $1(3.03)$ & $.49^{\mathrm{a}}$ \\
\hline Other Treatments & $3(8.82)$ & $0(0.00)$ & $.24^{\mathrm{a}}$ \\
\hline
\end{tabular}

a: Fisher's Exact Test

of SST), and at week 11 (after 10 weeks of social skills training).

\section{Secondary outcomes}

Several secondary outcome measures were included to capture different aspects of ASD that could be affected by the proposed treatment. When available, SRS data was collected from teachers of the subjects with ASD at baseline, week 6 , and week 11. Additionally, all participants were evaluated using the VABS-II, Aberrant Behavior Checklist (ABC) [39], Clinical Global Impression
Improvement Scale (CGI-I), and the TSSA, at baseline and week 11 .

The adaptive functioning of subjects was evaluated at baseline and week 11 using the VABS-II. The VABS-II assesses adaptive functioning in four domains: communication, daily living skills, socialization, and motor skills. Administered via semi-structured interview with parents or caregiver, the VABS-II provides a measure of overall functioning of children and adults. The VABS-II is a standardized, norm-referenced assessment that is used extensively in individuals with ASD [40, 41].

The $\mathrm{ABC}$ was collected at baseline, week 6 and week 11 to assess the impact of the treatment on symptoms relevant to ASD. The ABC is a 58 -item parent questionnaire with five subscales derived by factor analysis: irritability, social withdrawal, stereotypy, hyperactivity, and inappropriate speech. The $\mathrm{ABC}$ has been extensively used in psychopharmacological studies of ASD [42]. When available, teachers of the subjects with ASD were also asked to complete the $\mathrm{ABC}$ at the same time points.

The CGI-I was utilized as a clinician-rated dichotomous outcome measure to assess response to treatment. A trained clinician blind to treatment assignment rated the CGI-S at baseline and the CGI-I at each visit following randomization. Factors included in rating the CGI-I included parent report, parent-rated measures, teacherrated measures, and clinician-rated measures. The CGI-I provides a qualitative measure of treatment response through a rating from 1 to $7(1=$ very much improved; $2=$ much improved; $3=$ minimally improved; $4=$ no change; $5=$ minimally worse; $6=$ much worse; $7=$ very much worse). Rater training was conducted with gold standard vignettes and inter-rater reliability of $80 \%$ or greater was established. At the end of treatment, subjects with a CGI-I of "1" or " 2 " were categorized as responding to the treatment and subjects with CGI-I scores of " 3 " or higher were categorized as nonresponders.

To assess the impact of the treatment on social skills and social knowledge, the TSSA was administered to the subjects and their parents at baseline and week 11. The TSSA is a criterion-based assessment that addresses three components of social knowledge and skills: cognitive (ability to problem-solve interpersonal conflicts), behavioral (ability to initiate and maintain interactions and respond appropriately to others), and affective (ability to understand emotions). The TSSA has been used as a supplemental descriptive measure of social skills [43], as well as in treatment planning [44]. Other outcome measures collected included eye tracking data and direct behavioral observations (not reported in the present paper).

Finally, monitoring for AEs was completed at each visit for subjects with ASD. The site physician kept a log of AEs that included the date of onset, date of 
resolution, severity, and relationship to study intervention (e.g., definite, probable, possible, remote, or none).

Parental satisfaction with the study and social skills training group was measured via questionnaire at the end of the study (week 11). Parents were asked to answer the question, "participating in this group was worthwhile for my family", on a five-point Likert scale with "1" being anchored to "strongly disagree" and "5" being "strongly agree".

\section{Statistical analysis}

Study participants' demographic and clinical characteristics were summarized and compared between the DCS and placebo groups at baseline using two-sample $t$ tests for continuous variables and Fisher's exact tests for categorical variables. The change scores of the primary outcome variables (SRS total score and subscales) from baseline to 11-week follow-up were also compared between the two treatment groups using $t$ tests. Similar analyses were conducted for the secondary outcomes including VABS-II total score and subscales, ABC subscales, and TSSA parent report. In addition, a linear mixed-effects modeling was used to further test the treatment effect over time using longitudinal SRS total scores measured at baseline, 6-week and 11-week visits. Responder analysis (responders were defined as "much improved" or "very much improved" for CGI-I at 11week follow-up) was conducted using chi-square test. AEs during the treatment period were also analyzed. All analyses were performed using SAS version 9.2.

\section{Results}

Thirty-four participants were randomized to the DCS treatment group, and 33 were randomized to the placebo group. One subject who was randomized to the placebo group dropped out of the study before taking any medication and subsequently was excluded from the analysis. Comparisons between the two groups showed no statistically significant difference in age, sex, SB-V scores, the VABS-II Expressive Language subscale, the CGI-S, concomitant medications, or concomitant therapy treatments at baseline (Table 1). Therefore, no potential confounders were adjusted for as covariates in all subsequent analyses. Furthermore, no significant differences were noted between the two sites (Cincinnati and Indiana University) on demographic variables (Table 2).

No statistically significant difference attributable to drug treatment was observed in the change scores for the SRS total score $(p=0.45)$. The SRS subscale scores were evaluated as an exploratory analysis and were also not statistically significant. Additionally, no significant differences that were identified between groups in the change scores for the secondary outcome measures were identified (Table 3). In addition, teacher-rated ABC data
Table 2 Sample characteristics at enrollment across sites

\begin{tabular}{|c|c|c|c|}
\hline Characteristics & $\begin{array}{l}\text { Cincinnati } \\
(n=15)\end{array}$ & $\begin{array}{l}\text { Indiana } \\
\text { University } \\
(\mathrm{n}=52)\end{array}$ & p-value \\
\hline \multicolumn{4}{|l|}{ Demographics } \\
\hline Age (years), mean (SD) & $8.56(1.77)$ & $8.24(1.84)$ & .56 \\
\hline Sex, n (\%) male & $11(73.33)$ & $44(84.62)$ & $.44^{\mathrm{a}}$ \\
\hline Group, n (\%) Cycloserine & $8(53.33)$ & $26(50.00)$ & .82 \\
\hline \multicolumn{4}{|l|}{ Clinical Variables } \\
\hline \multicolumn{4}{|l|}{ Stanford-Binet V, mean (SD) } \\
\hline Full Scale IQ & $87.86(13.78)$ & $90.40(17.67)$ & .62 \\
\hline NonVerbal IQ & $92.57(15.36)$ & $93.10(17.17)$ & .92 \\
\hline Verbal IQ & 85.29 (14.19) & $88.92(18.94)$ & .51 \\
\hline $\begin{array}{l}\text { VABS-II Expressive Language } \\
\text { subscale standard score, mean (SD) }\end{array}$ & $84.67(9.76)$ & $86.37(15.21)$ & .68 \\
\hline Clinical Global Impression-Severity & $4.00(0.00)$ & $4.06(0.24)$ & .38 \\
\hline \multicolumn{4}{|l|}{ Diagnosis, n (\%) } \\
\hline PDD-NOS & $9(60.00)$ & $18(34.62)$ & .08 \\
\hline Autistic Disorder & $4(26.67)$ & $4(7.69)$ & $.07^{\mathrm{a}}$ \\
\hline Asperger's Disorder & $2(13.33)$ & $30(57.69)$ & $.003^{\mathrm{a}^{*}}$ \\
\hline \multicolumn{4}{|l|}{ Concomitant medications, n (\%) } \\
\hline Antipsychotics & $2(13.33)$ & $14(26.92)$ & $.49^{\mathrm{a}}$ \\
\hline Alpha-2 Agonists & $3(20.00)$ & $11(21.15)$ & $1.00^{\mathrm{a}}$ \\
\hline Stimulants & $8(53.33)$ & $17(32.69)$ & .15 \\
\hline Sleep Aids & $3(20.00)$ & $13(25.00)$ & $1.00^{\mathrm{a}}$ \\
\hline Mood Stabilizers & $0(0.00)$ & $3(5.77)$ & $1.00^{\mathrm{a}}$ \\
\hline Glutamatergic Modulators & $0(0.00)$ & $1(1.92)$ & $1.00^{\mathrm{a}}$ \\
\hline Other & $1(6.67)$ & $3(5.77)$ & $1.00^{\mathrm{a}}$ \\
\hline \multicolumn{4}{|l|}{ Concomitant treatment, n (\%) } \\
\hline Speech Therapy & $6(40.00)$ & $30(57.69)$ & .23 \\
\hline Occupational Therapy & $6(40.00)$ & $21(40.38)$ & .98 \\
\hline Behavioral Therapy & $2(13.33)$ & $16(30.77)$ & $.32^{\mathrm{a}}$ \\
\hline Other Psychotherapy & $0(0.00)$ & $3(5.77)$ & $1.00^{\mathrm{a}}$ \\
\hline Physical Therapy & $1(6.67)$ & $1(1.92)$ & $.40^{\mathrm{a}}$ \\
\hline Social Skills Training & $1(6.67)$ & $4(7.69)$ & $1.00^{\mathrm{a}}$ \\
\hline Music Therapy & $1(6.67)$ & $0(0.00)$ & $.22^{\mathrm{a}}$ \\
\hline Other Treatments & $1(6.67)$ & $2(3.85)$ & $.54^{\mathrm{a}}$ \\
\hline
\end{tabular}

a: Fisher's Exact Test

was returned for $23.5 \%$ of the DCS group, and $30.3 \%$ of the placebo group with no significant difference noted for any of the $\mathrm{ABC}$ subscales (irritability $p=0.623$, social withdrawal $p=0.845$, stereotypy $p=0.434$, hyperactivity $p=0.833$, and inappropriate speech $p=0.959$ ) between groups. Teacher-rated SRS data was available for $26.4 \%$ of the DCS group and $27.2 \%$ of the placebo group, and again, no significant difference was found between groups $(p=0.59)$. Finally, at week 11 , parental satisfaction was found to be high across both groups $(96 \%$ and 
Table 3 Baseline, Week 11, and change in primary and secondary outcome measures

\begin{tabular}{|c|c|c|c|c|c|c|c|c|}
\hline \multirow[t]{3}{*}{ Clinical Outcome } & \multicolumn{3}{|l|}{ DCS $(n=34)$} & \multicolumn{3}{|l|}{ Placebo $(n=33)$} & \multirow[b]{3}{*}{$\begin{array}{l}\text { Difference in Change } \\
\text { Scores }(95 \% \mathrm{Cl})\end{array}$} & \multirow[b]{3}{*}{ P-valu } \\
\hline & \multicolumn{3}{|l|}{ Mean (SD) } & \multicolumn{3}{|l|}{ Mean (SD) } & & \\
\hline & Baseline & 11-week & Change & Baseline & 11-week & Change & & \\
\hline \multicolumn{9}{|l|}{ Primary outcome } \\
\hline \multicolumn{9}{|c|}{ Social Responsiveness Scale (SRS) Parent Raw Scores } \\
\hline Social awareness & $12.82(3.43)$ & $12.15(2.73)$ & $-0.76(2.60)$ & $13.82(3.59)$ & $12.94(2.67)$ & $-1.00(3.12)$ & $0.24(-1.19$ to 1.67$)$ & .74 \\
\hline Social cognition & $19.18(5.37)$ & $17.21(6.01)$ & $-1.94(4.41)$ & $20.88(4.34)$ & $18.06(4.24)$ & $-2.68(3.74)$ & $0.74(-1.31$ to 2.79$)$ & .47 \\
\hline Social communication & $34.94(8.65)$ & $30.00(8.55)$ & $-4.91(6.49)$ & $37.97(7.84)$ & $32.03(7.71)$ & $-6.19(8.40)$ & $1.28(-2.45$ to 5.02$)$ & .49 \\
\hline Social motivation & $16.06(5.84)$ & $13.18(5.01)$ & $-2.76(3.95)$ & $16.33(5.34)$ & $13.39(5.17)$ & $-3.06(4.40)$ & 0.31 (-1.78 to 2.40$)$ & .54 \\
\hline Autistic mannerisms & $19.44(6.10)$ & $16.42(6.03)$ & $-2.82(5.24)$ & $21.42(6.27)$ & $17.65(5.36)$ & $-4.10(6.38)$ & $1.28(-1.63$ to 4.19$)$ & .38 \\
\hline SRS Parent Total Score & $102.35(25.09)$ & $88.67(22.74)$ & $-13.39(16.81)$ & $110.33(20.43)$ & $94.00(19.31)$ & $-17.00(21.33)$ & $3.61(-5.96$ to 13.17$)$ & .45 \\
\hline \multicolumn{9}{|l|}{ Secondary outcomes } \\
\hline \multicolumn{9}{|l|}{ VABS-II raw scores } \\
\hline Communication & $152.56(17.05)$ & $156.47(17.85)$ & $3.63(8.26)$ & $147.06(22.18)$ & $154.58(21.93)$ & $6.77(11.15)$ & $-3.15(-8.08$ to 1.79$)$ & .21 \\
\hline Daily living skills & $231.62(26.08)$ & $239.56(26.99)$ & $7.06(14.72)$ & 229.67 (35.43) & $239.29(35.76)$ & $8.45(16.82)$ & $-1.39(-9.35$ to 6.57$)$ & .73 \\
\hline Socialization & $113.26(24.98)$ & $126.53(27.54)$ & $12.34(20.00)$ & $103.97(22.14)$ & $117.35(27.94)$ & $12.10(22.28)$ & $0.25(-10.41$ to 10.91$)$ & .96 \\
\hline Motor skills & $141.21(7.21)$ & $143.59(5.42)$ & $2.22(5.70)$ & $141.27(9.50)$ & 142.19 (9.59) & $0.19(3.81)$ & $2.03(-0.41$ to 4.46$)$ & .10 \\
\hline Maladaptive behavior & $16.65(6.87)$ & $15.88(7.12)$ & $-0.59(5.92)$ & $18.55(7.42)$ & $16.42(5.59)$ & $-2.03(5.91)$ & $1.44(-1.54$ to 4.42$)$ & .34 \\
\hline Total & $655.29(59.88)$ & $682.03(64.28)$ & 24.66 (37.56) & $640.52(78.65)$ & $669.84(83.74)$ & $25.48(41.11)$ & $-0.83(-20.66$ to 19.00$)$ & .93 \\
\hline \multicolumn{9}{|l|}{$A B C$ parent score } \\
\hline Irritability & $11.06(8.05)$ & $9.12(6.63)$ & $-1.55(6.11)$ & $12.67(8.96)$ & $11.06(7.42)$ & $-1.23(6.09)$ & $-0.32(-3.37$ to 2.73$)$ & .83 \\
\hline Social Withdrawal & $10.29(8.30)$ & $8.06(7.61)$ & $-2.39(4.71)$ & $10.39(8.33)$ & $8.81(6.41)$ & $-1.71(7.04)$ & $-0.68(-3.71$ to 2.34$)$ & .65 \\
\hline Stereotypy & $4.94(4.21)$ & $4.64(4.89)$ & $-0.33(2.79)$ & $4.64(4.32)$ & $4.32(3.75)$ & $-0.45(4.60)$ & $0.12(-1.81$ to 2.04$)$ & .90 \\
\hline Hyperactivity & $18.82(11.26)$ & $17.30(12.23)$ & $-1.55(7.37)$ & $19.00(9.18)$ & $16.87(9.49)$ & $-2.03(9.39)$ & $0.49(-3.72$ to 4.69$)$ & .82 \\
\hline Inappropriate speech & $3.91(3.04)$ & $3.24(2.26)$ & $-0.73(2.59)$ & $4.36(2.85)$ & $4.68(3.29)$ & $0.35(2.67)$ & $-1.08(-2.40$ to 0.23$)$ & .10 \\
\hline TSSA parent & $53.74(8.61)$ & $57.84(9.11)$ & 3.88 (3.49) & $48.79(8.91)$ & $54.34(10.37)$ & $5.83(9.70)$ & $-1.95(-6.87$ to 2.97$)$ & .43 \\
\hline
\end{tabular}

$88 \%$ for DCS and placebo groups, respectively, rated satisfaction as a 4 or 5 on the five-point Likert scale). A Fisher's exact test demonstrated no significant difference in the level of parental satisfaction $(p=0.33)$.

In addition to the primary endpoint of the study at week 11, the SRS total score was also measured at week 6. A linear mixed-effects model was fitted to further test the treatment effect over time using data at all three visits. Again, there was no significant difference between the two treatment groups $(p=0.502)$. The repeated measures of the SRS total scores are depicted in Fig. 1.

A responder analysis was conducted based on CGI-I scores at 11-week follow-up. For the responder analysis, $33.3 \%$ of participants in the DCS group were classified as responders to treatment based on the CGI-I, as compared to $32.3 \%$ in the placebo group, which showed no significant difference in rate of response between groups $(p=0.927)$. Based on the observed trend of improvement in both treatment groups, subjects were combined to assess whether SRS total score changed significantly from baseline to week 11. A paired $t$ test for all 67 subjects with ASD showed a mean change score of -15.14 with $95 \%$ confidence interval $(-19.90,-10.38)$, $p<0.0001$.

\section{Adverse events}

Table 4 shows the number of subjects who reported an adverse event, as well as all categories of AEs where at least $10 \%$ of either group (DCS or placebo) reported experiencing that AE. Fisher's exact tests were utilized to derive $p$ values. No category of adverse event showed a statistically significant difference between groups. The DCS group experienced more emesis than the placebo group (17.6 vs. $6.1 \%, p=0.26$ ). Overall, more patients in the DCS group reported at least one adverse event compared to the placebo group ( 94.2 vs. $84.8 \%$ ), although this difference was not significant $(p=0.21)$. The placebo group had a higher number of total adverse events (149 vs. 138$)(p=0.87)$. Finally, only one 


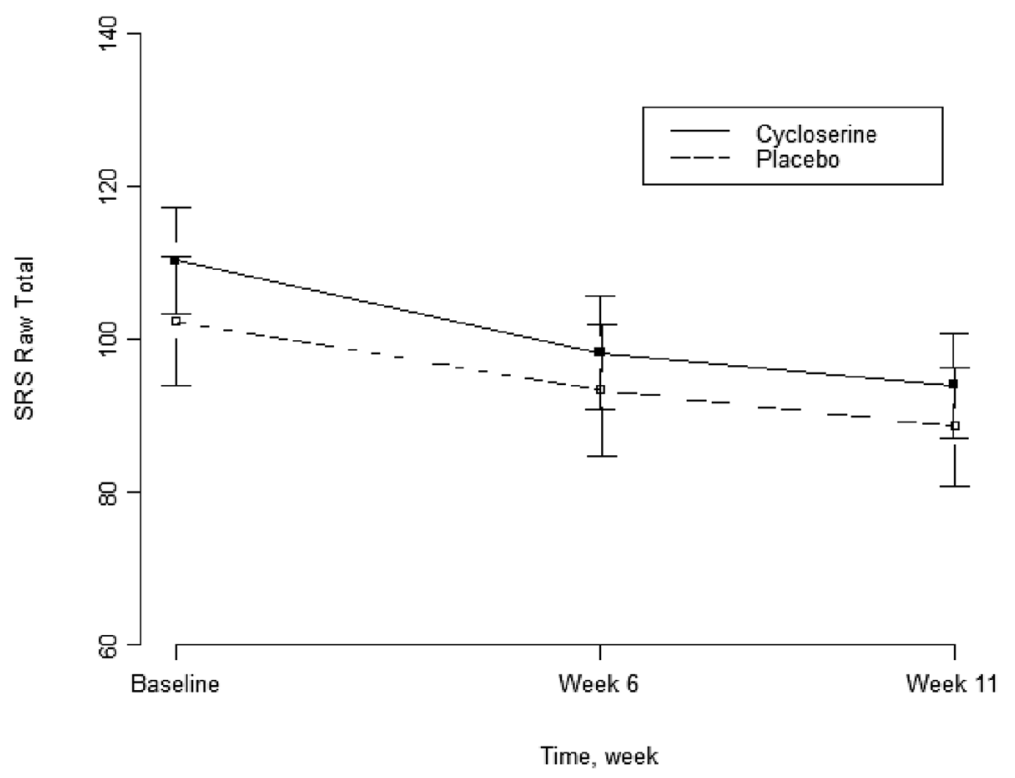

Fig. 1 Social responsiveness scale raw score across time points

serious adverse event (one instance of making a suicidal comment at school when angry) was reported in the placebo group.

\section{Discussion}

The core social deficits seen in ASD are severely impairing, and few interventions have been identified to successfully and consistently treat these impairments. Several promising studies have shown DCS to enhance behavioral therapy outcomes in individuals with anxiety disorders, as well as demonstrating potential benefits of DCS treatment in ASD. The present study extended these lines of study by evaluating DCS-mediated enhancement of the learning of social skills in children with ASD. The results of this double-blind placebo-controlled short-term trial demonstrate no drug-related improvement on the primary outcome measure, or any of the secondary outcome measures. However, an overall significant improvement in SRS total raw score was observed from baseline to end of treatment for the entire group of children with ASD.

Table 4 Adverse events by treatment group

\begin{tabular}{|c|c|c|c|}
\hline \multirow[b]{2}{*}{ Adverse Event } & \multicolumn{2}{|c|}{ Number (\%) of patients reporting } & \multirow[b]{2}{*}{$\mathrm{p}$ value } \\
\hline & $\overline{D C S}(\mathrm{~N}=34)$ & Placebo $(\mathrm{N}=33)$ & \\
\hline Any Adverse Event & $32(94.1)$ & $28(84.8)$ & 0.26 \\
\hline Headache (including sinus headache) & $9(26.5)$ & $7(21.2)$ & 0.80 \\
\hline Nasal congestion or Cold & $6(17.6)$ & $8(24.2)$ & 0.79 \\
\hline Cough & $7(20.6)$ & $7(21.2$ & 0.99 \\
\hline Vomiting & $6(17.6)$ & $2(6.1)$ & 0.29 \\
\hline Aggression & $2(5.9)$ & $5(15.2)$ & 0.45 \\
\hline Increased motor activity & $1(2.9)$ & $5(15.2)$ & 0.22 \\
\hline Interrupted sleep/ other sleep problems & $3(8.8)$ & $5(15.2)$ & 0.73 \\
\hline Irritability (including agitation) & $16(47.1)$ & $15(45.5)$ & 0.99 \\
\hline Restlessness/Agitation & $4(11.8)$ & $3(9.1)$ & 0.99 \\
\hline Sadness & $5(14.7)$ & $3(9.1)$ & 0.73 \\
\hline Sedation/Drowsiness & $2(5.9)$ & $6(18.2)$ & 0.29 \\
\hline Not otherwise listed & $10(29.4)$ & $12(36.4)$ & 0.83 \\
\hline Any Serious Adverse Event & 0 & $1(3.0)$ & 0.99 \\
\hline
\end{tabular}


There are several possible explanations for the lack of pharmacological treatment effect in this study. Notably, the large increase in SRS scores observed in both the DCS and placebo groups is greater than that seen in other intervention studies [45]. This may be explained by the novelty of the social skills training group, something that had previously may have been unavailable to the participants. Therefore, demonstrating the added benefits of DCS to an already high placebo response rate may be very difficult. Also, the SRS was collected immediately following the 10-week trial, which does not allow for the assessment of the durability of these findings.

Another potential explanation for the lack of drug effect may be the heterogeneity of ASD, which makes this a particularly challenging population to study and all the more difficult to find effective pharmacological and behavioral interventions. It is also important to note that since study enrollment ended, the Diagnostic and Statistical Manual of Mental Disorders, Fifth Edition (DSM-5) [46] has been published with revisions resulting in a new category of diagnosis called autism spectrum disorder, along with the restructuring of diagnostic criteria. However, we do not believe that these diagnostic changes would have influenced the results of the current study.

Another potential reason for the lack of drug effect in the current study is that social interactions, and therefore social deficits, are difficult behaviors to objectively quantify due to the ways in which social behavior changes in different settings and circumstances and over time. This study utilized the parent-rated SRS total raw score to evaluate social deficits in ASD. The SRS provides a global perspective on social deficits in ASD. However, the learning occurring during social skills training may not produce effects sufficiently robust to alter these broad, subjective social skills ratings. In the future, a more direct, objective measurement of social behavior and social interest, such as eye tracking, may be required to capture change in social interaction which occurs at a level not readily observable by caregivers and clinicians.

Several additional factors should be considered in evaluating the findings of the current study. Based on the effective dose of DCS used in the studies of DCS plus therapy for treatment of phobias and social anxiety, all subjects in this trial received $50 \mathrm{mg}$ of DCS regardless of weight $[47,48]$. It is possible that higher doses (potentially weight based) may have resulted in greater improvement for the DCS group. However, the phobia study by Ressler et al. [47] demonstrated no difference between 50 and $500 \mathrm{mg}$ doses of DCS, so it is unclear what impact dosage adjustment may have provided [47]. Longer duration and more frequent treatment may also need to be considered. Ten weekly doses of DCS and social skills training may not be sufficient to make robust changes in symptoms of social impairment and extended length of treatment and/or daily dosing may be necessary. In addition, the psychotherapy studies referenced in the development of this protocol dealt with operant conditioning via learned extinction. The current study not only utilized some operant conditioning techniques (such as reinforcement) but also used other learning mechanisms in the training of social skills (such as social learning through modeling and role playing). It is possible that DCS has its greatest influence over learned extinction, and our negative results may reveal the limitation of our employed learning mechanism.

Finally, a limitation of this study is the novelty of the social skills training curriculum and lack of a control for the social skills training group. This curriculum was novel and its effects were previously unknown. In addition, treatment fidelity data was not collected and other standardized behavioral and social skills outcome measures, such as the Social Skills Improvement System [49], or other emotion recognition measures [24] were not utilized. All children enrolled in the study received 10 weeks of social skills training, and statistically significant improvements were seen across the outcome measures when drug and placebo groups were combined. These results may point to the efficacy of this social skills training protocol at improving social outcomes for children with ASD. However, this potential mechanism cannot be confirmed without controlling for other factors that potentially influenced the results, such as maturation, time with trained clinicians, attention, and access to peers. A placebo or waitlist control group should be employed in future studies to evaluate the efficacy of our social skills curriculum.

\section{Conclusions}

The present study provides proof of concept that a large sample study combining medication and social skills training in ASD is feasible. Few studies have been conducted in ASD combining pharmacological and behavioral interventions, despite the common blending of these interventions in clinical settings. Future research on the role of targeted drug treatments in augmenting behavioral interventions in ASD is warranted. Despite the negative result of this short-term drug augmentation analysis, we believe that further work focused on durability of treatment response is needed to assess longterm outcome following initial combination treatment in this and other similar projects. Overall, utilizing targeted drug treatment to facilitate learning and acquisition of skills during therapy in ASD warrants additional investigation. Lessons learned in our study of DCS as a potential augmentation strategy to social skills training lay the groundwork for such work. 


\section{Abbreviations}

ASD: autism spectrum disorders; DCS: D-cycloserine; SRS: social responsiveness scale; SB-V: Stanford-Binet 5th edition; VABS-II: Vineland adaptive behavior scale 2nd edition; TSSA: Triad social skills assessment; CGI-S: clinical global impressionseverity; TPs: typically-developing peer models; AEs: adverse events; PDDNOS: pervasive developmental disorder not otherwise specified; ABA: applied behavior analysis; ABC: aberrant behavior checklist; CGI-l: clinical global impression improvement scale; DSM-5: Diagnostic and Statistical Manual of Mental Disorders, Fifth Edition.

\section{Competing interests}

The authors declare that they have no competing interests.

\section{Authors' contributions}

NM and CE served as primary investigators for the study and participated in all aspects of the study and in preparation of the manuscript. LW, RS, MP, and $\mathrm{SH}$ participated in participant assessments, the implementation of the study protocol, and preparation of the manuscript. HL performed the statistical analyses and helped to revise the manuscript. DP, NS, and CM participated in the design of the study and helped to revise the manuscript. All authors read and approved the final manuscript.

\section{Acknowledgements}

Funding for this study was provided by the United States Department of Defense Award Number W81XWH-09-1-0091. Statistical support was provided by Hai Liu, Ph.D., Indiana University School of Medicine Department of Biostatistics. We would like to acknowledge the contributions of Stacie Pozdol, M.A., Carrie McGinnis, B.S., CCRP, and Lyndsi Moser, B. S., CCRP at Indiana University, and Katherine Friedmann, RN, Lauren Mathieu-Frasier, MA, and Tori Schaefer, PhD at Cincinnati Children's Hospital Medical Center.

\section{Author details}

${ }^{1}$ Christian Sarkine Autism Treatment Center, Riley Hospital for Children at Indiana University Health, Indiana University School of Medicine Department of Psychiatry, Indianapolis, IN, USA. ${ }^{2}$ Cincinnati Children's Hospital Medical Center, University of Cincinnati College of Medicine, 3333 Burnet Avenue MLC 4002, Cincinnati, OH 45229, USA. ${ }^{3}$ David J. Posey, M.D., LLC, Indianapolis, IN, USA. ${ }^{4}$ Department of Biostatistics, Indiana University School of Medicine, Indianapolis, IN, USA. ${ }^{5}$ Indiana University School of Education, Bloomington, IN, USA. 'urie Center for Autism, Departments of Psychiatry and Pediatrics, Massachusetts General Hospital and MassGeneral Hospital for Children, Harvard Medical School, Boston, MA, USA.

\section{Received: 1 June 2015 Accepted: 14 December 2015}

\section{Published online: 14 January 2016}

\section{References}

1. Kanner L. Autistic disturbances of affective contact. Nervous Child 1943:2:217-50

2. CDC. Prevalence of autism spectrum disorder among children aged 8 years - autism and developmental disabilities monitoring network, 11 sites, United States, Contract No.: 2. 2010.

3. Wink LK, Erickson CA, McDougle CJ. Pharmacologic treatment of behavioral symptoms associated with autism and other pervasive developmental disorders. Curr Treat Options Neurol. 2010;12(6):529-38. doi:10.1007/s11940-010-0091-8.

4. Blankenship K, Stigler KA, Erickson CA, Posey DJ, McDougle CJ. Psychopharmacoloigcal treatment of autism. In: Amaral D, Dawson G, Geschwind D, editors. Autism spectrum disorders. New York: Oxford University Press; 2011. p. 1194-212.

5. Posey DJ, Erickson CA, McDougle CJ. Developing drugs for core social and communication impairment in autism. Child Adolesc Psychiatr Clin N Am. 2008;17(4):787-801. doi:10.1016/j.chc.2008.06.010. viii-ix.

6. Magiati I, Tay XW, Howlin P. Cognitive, language, social and behavioural outcomes in adults with autism spectrum disorders: a systematic review of longitudinal follow-up studies in adulthood. Clin Psychol Rev. 2014;34(1):73-86.

7. McDougle CJ, Erickson CA, Stigler KA, Posey DJ. Neurochemistry in the pathophysiology of autism. J Clin Psychiatry. 2005;66 Suppl 10:9-18.

8. Goff DC, Tsai G, Levitt J, Amico E, Manoach D, Schoenfeld DA, et al. A placebo-controlled trial of D-cycloserine added to conventional neuroleptics in patients with schizophrenia. Arch Gen Psychiatry. 1999;56(1):21-7.
9. van Berckel BN, Evenblij CN, van Loon BJ, Maas MF, van der Geld MA, Wynne HJ, et al. D-cycloserine increases positive symptoms in chronic schizophrenic patients when administered in addition to antipsychotics: a double-blind, parallel, placebo-controlled study. Neuropsychopharmacology. 1999;21(2):203-10. doi:10.1016/s0893-133x(99)00014-7.

10. Goff DC, Cather C, Gottlieb JD, Evins AE, Walsh J, Raeke L, et al. Once-weekly D-cycloserine effects on negative symptoms and cognition in schizophrenia: an exploratory study. Schizophr Res. 2008;106(2-3):320-7. doi:10.1016/j.schres.2008.08.012.

11. Goff DC, Herz L, Posever T, Shih V, Tsai G, Henderson DC, et al. A six-month, placebo-controlled trial of D-cycloserine co-administered with conventional antipsychotics in schizophrenia patients. Psychopharmacology. 2005;179(1): 144-50. doi:10.1007/s00213-004-2032-2.

12. Duncan EJ, Szilagyi S, Schwartz MP, Bugarski-Kirola D, Kunzova A, Negi S, et al. Effects of D-cycloserine on negative symptoms in schizophrenia. Schizophr Res. 2004;71(2-3):239-48. doi:10.1016/j.schres.2004.03.013.

13. Posey DJ, Kem DL, Swiezy NB, Sweeten TL, Wiegand RE, McDougle CJ. A pilot study of D-cycloserine in subjects with autistic disorder. Am J Psychiatry. 2004;161(11):2115-7. doi:10.1176/appi.ajp.161.11.2115.

14. Posey DJ, Stigler KA, Erickson CA, Azzouz F, Wilkerson J, Mullett J, et al., editors. A double-blind, placebo-controlled study of D-cycloserine in children with autistic disorder, American College of Neuropsychopharmacology 46th Annual Meeting 2007 December 9-13. Boca Raton: American College of Neuropsychopharmacology; 2007.

15. Swanson CJ, Bures M, Johnson MP, Linden A-M, Monn JA, Schoepp DD. Metabotropic glutamate receptors as novel targets for anxiety and stress disorders. Nat Rev Drug Discov. 2005;4(2):131-44.

16. Cortese BM, Phan $\mathrm{KL}$. The role of glutamate in anxiety and related disorders. CNS Spectrums. 2005;10(10):820-30.

17. Norberg MM, Krystal JH, Tolin DF. A meta-analysis of D-cycloserine and the facilitation of fear extinction and exposure therapy. Biol Psychiatry. 2008; 63(12):1118-26. doi:10.1016/j.biopsych.2008.01.012.

18. Rodrigues H, Figueira I, Lopes A, Goncalves R, Mendlowicz MV, Coutinho ES, et al. Does D-cycloserine enhance exposure therapy for anxiety disorders in humans? A meta-analysis. PLoS One. 2014;9(7), e93519. doi:10.1371/journal. pone.0093519.

19. Modi ME, Young LJ. D-cycloserine facilitates socially reinforced learning in an animal model relevant to autism spectrum disorders. Biol Psychiatry. 2011;70(3):298-304. doi:10.1016/j.biopsych.2011.01.026.

20. Foxx RM. Applied behavior analysis treatment of autism: the state of the art. Child Adolesc Psychiatr Clin N Am. 2008;17(4):821-34.

21. Scattone D, Tingstrom DH, Wilczynski SM. Increasing appropriate social interactions of children with autism spectrum disorders using social stories. Focus Autism Other Developmental Disabilities. 2006;21(4):211-22. doi:10.1177/10883576060210040201.

22. Schneider N, Goldstein H. Using social stories and visual schedules to improve socially appropriate behaviors in children with autism. J Posit Behav Interv. 2010;12(3):149-60.

23. Koegel L, Vernon T, Koegel RL, Koegel B, Paullin AW. Improving socialization between children with autism spectrum disorder and their peers in inclusive settings. J Posit Behav Interv. 2012;14(4):220-7.

24. Reichow B, Volkmar FR. Social skills interventions for individuals with autism: evaluation for evidence-based practices within a best evidence synthesis framework. J Autism Dev Disord. 2010;40:149-66.

25. Stone W, Ruble L, Coonrod E, Hepburn S, Pennington M. TRIAD social skills assessment manual. Nashville, TN: Treatment and Research Institute for Autism Spectrum Disorders; 2003

26. Pozdol SL SN, Stuart ML, Beach EB, Beach EB, editors. Social skills training in children with ASD: a comparison of weekly groups and summer camp formats. Annual convention of the association for behavior analysis. Social skills training in children with ASD: a comparison of weekly groups and summer camp formats. Annual convention of the Association for Behavior Analysisth ed. San Diego: Association for Behavior Analysis; 2007.

27. Lord C, Rutter M, Goode S, Heemsbergen J, Jordan H, Mawhood L, et al. Autism diagnostic observation schedule: a standardized observation of communicative and social behavior. J Autism Dev Disord. 1989;19(2):185-212.

28. Gotham K, Risi S, Pickles A, Lord C. The autism diagnostic observation schedule: revised algorithms for improved diagnostic validity. J Autism Dev Disord. 2007;37(4):613-27. doi:10.1007/s10803-006-0280-1. 
29. Lord C, Pickles A, McLennan J, Rutter M, Bregman J, Folstein S, et al. Diagnosing autism: analyses of data from the autism diagnostic interview. J Autism Dev Disord. 1997;27(5):501-17.

30. Association AP. Diagnostic and statistical manual of mental disorders, fourth edition, text revision. Washington, DC: American Psychiatric Association; 2000

31. Roid GH. Stanford-Binet intelligence scales for early childhood, Early SB5. Fifthth ed. 2005.

32. Sparrow SS, Cicchetti DV, Balla DA. Vineland adaptive behavior scales, Vineland-II. Secondth ed. 2008.

33. Constantino JN, Gruber CP. Social responsiveness scale. 2005.

34. Sprafkin J, Gadow KD. Child symptom inventory 4. 2002.

35. Marrus N, Underwood-Riordan H, Randall F, Zhang Y, Constantino JN. Lack of effect of risperidone on core autistic symptoms: data from a longitudinal study. J Autism Dev Disord. 2014;24(9):513-8. doi:10.1089/cap.2014.0055.

36. Lyall K, Constantino JN, Weisskopf MG, Roberts AL, Ascherio A, Santangelo SL Parental social responsiveness and risk of autism spectrum disorder in offspring. JAMA Psychiatry. 2014;71(8):936-42. doi:10.1001/jamapsychiatry.2014.476.

37. Erickson CA, Veenstra-Vanderweele JM, Melmed RD, McCracken JT, Ginsberg LD, Sikich L, et al. STX209 (arbaclofen) for autism spectrum disorders: an 8-week open-label study. J Autism Dev Disord. 2014;44(4):958-64. doi:10.1007/s10803-013-1963-z.

38. Hardan AY, Fung LK, Libove RA, Obukhanych TV, Nair S, Herzenberg LA, et al. A randomized controlled pilot trial of oral $\mathrm{N}$-acetylcysteine in children with autism. Biol Psychiatry. 2012;71(11):956-61. doi:10.1016/j.biopsych.2012.01.014.

39. Aman MG, Singh NN. Aberrant behavior checklist, ABC. 1986.

40. Fisch GS. Adaptive behavior in children with autism. J Autism Dev Disord. 2001;31(2):249

41. Freeman BJ, Del'Homme M, Guthrie D, Zhang F. Vineland adaptive behavior scale scores as a function of age and initial IQ in 210 autistic children. J Autism Dev Disord. 1999;29(5):379-84.

42. McCracken JT, McGough J, Shah B, Cronin P, Hong D, Aman MG, et al. Risperidone in children with autism and serious behavioral problems. N Engl J Med. 2002:347(5):314-21. doi:10.1056/NEJMoa013171.

43. Murray DS, Ruble LA, Willis H, Molloy CA. Parent and teacher report of social skills in children with autism spectrum disorders. Lang Speech Hear Serv Sch. 2009:40(2):109-15.

44. Ruble L, Willis H, Crabtree VM. Social skills group therapy for autism spectrum disorders. Clinical Case Studies. 2008;7(4):287-300.

45. Guastella AJ, Gray KM, Rinehart NJ, Alvares GA, Tonge BJ, Hickie IB, et al. The effects of a course of intranasal oxytocin on social behaviors in youth diagnosed with autism spectrum disorders: a randomized controlled trial. J Child Psychol Psychiatry. 2015;56(4):444-52. doi:10.1111/jcpp.12305.

46. American Psychiatric Association. Diagnostic and statistical manual of mental disorders: DSM-5 ${ }^{\text {TM }}$ (5th ed.). Arlington, VA, US: American Psychiatric Publishing, Inc.; 2013.

47. Ressler K, Rothbaum BO, Tannenbaum L, Anderson P, Graap K, Zimand E, et al. Cognitive enhancers as adjuncts to psychotherapy: use of D-cycloserine in phobic individuals to facilitate extinction of fear. Arch Gen Psychiatry. 2004;61(11):1136-44. doi:10.1001/archpsyc.61.11.1136.

48. Hofmann SG, Meuret AE, Smits JA, Simon NM, Pollack MH, Eisenmenger K, et al. Augmentation of exposure therapy with D-cycloserine for social anxiety disorder. Arch Gen Psychiatry. 2006;63(3):298-304. doi:10.1001/archpsyc.63.3.298

49. Gresham FM, Elliot SN. Social Skills Improvement system-rating scales. Minneapolis: Pearson Assessments; 2008.

\section{Submit your next manuscript to BioMed Central and we will help you at every step:}

- We accept pre-submission inquiries

- Our selector tool helps you to find the most relevant journal

- We provide round the clock customer support

- Convenient online submission

- Thorough peer review

- Inclusion in PubMed and all major indexing services

- Maximum visibility for your research

Submit your manuscript at www.biomedcentral.com/submit
Biomed Central 